\title{
A FAMILIA: UM: SUJEITO POUCO REFLETIDO NO MOVIMENTO DE LUTA PELOS DIREITOS DA CRIANÇA E DO ADOLESCENTE
}

\section{THE FAMILY: A SUBJECT LITTLE CONSIDERED IN THE FIGHT MOVEMENT FOR THE RIGHTS OF THE CHILD AND ADOLESCENT}

Maria do Carmo B. de Carvalho ${ }^{1}$

Isa Mana F. da Rosa Guará ${ }^{2}$

CARVALHO, M. C. B.; GUARÁ, I. M. F. R. A Familia: Um Sujeito Pouco Refletido no Movimento de Luta pelos Direitos da Crianca e do Adolescente. Rev. Bras. Crésc. Des. Hum., São Paulo, IV(1), 1994.

Resumo: Neste texto as autoras mostram que é necessário desmistificar a visão que se tem da família como incapaz, desestruturada e culpada pela situação vulnerável de seus filhos

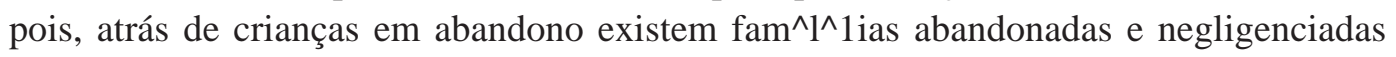
pela politica de assistência social.

A família deve ser reconhecida como provedora básica das necessidades de seus filhos e como sujeito coletivo de direitos; ampliando-se para ela, a mesma proteção reivindicada para crianças, idosos, mulheres..., através de uma “Rede de Atenção Integrada”, entre serviços e instituicões, incluindo-se aí, a proteção social, jurídica e econômica.

Palavras-chave: familia, politicas públicas, direitos sociais, proteção social jurídicoeconômico.

Summary: In this text the authors show that it is necessary to reconsider the common view that the family is unable, disorganized and guilty for the vulnerable situation of their children, because behind abandoned children there are abandoned families, negletected by the policies of social assistance.

The family must be recognized as the basic supplier of their children's needs and as a collective subject of rights, amplifying to it the same protection vindicated to children, old people, women..., through a "Network of Integrated Attention", involving services and institutions and including social, legal and economic protection

Rey-words: family; public policies; social rights; social, legal and economic protection.

1 Doutora em Serviço Social, Professora do Programa de Estudos Pós-Graduados em Serviço Social - PUC/SP e Dirctota do instituto de Estudos Especiais da Pontifícia Universidade Cat61ica - IEE/PUC/SP.

End.: Rua Cardoso de Almeida, 990, Perdizes, São Paulo - SP, CEP 05013 001 - Fone (011) 625142.

2 Mestraoda em Serviço Social, Pesquisadora do IEE/PUC/SP. 
Temos falado com insistência (e muita pertinência) nos direitos de crianças e adolescentes à vida, ao pleno desenvolvimento, à proteção integral.

No cenário de direitos deste segmento, a família emerge como referência insuprimível. É ela que, em primeira instância, Besta, cria e assume a proteção de suas crianças e adolescentes.

A tendência contemporânea de fracionar os segmentos portadores de direitos (a criança, o adolescente, a mulher, o idoso...) acaba por embaçar as demandas de justiça e proteção do grupo familiar.

Famílias castigadas pela pobreza e exclusão quase só podem predestinar a seus filhos o mesmo horizonte de vida na exclusão. Percebemos pouco esta realidade que nos cerca, expressado de forma dramática pelo número de crianças abandonadas e nos internatos, pelo número de meninos(as) de e na rua, pelas crianças e adolescentes que trabalham, pelas crianças e adolescentes que se evadiram da escola muito precocemente, ...

Quase sempre observamos as crianças deslocadas de seu contexto familiar e a percepção de sua tragédia pode eventualmente conduzir a análises simplistas em que a culpabilização da família é uma das idéias recorrentes.

Esquecemos que a muito pouco tempo essa mãe ou esse pai eram adolescentes cuja situação por certo não terá sido muito diferente da que hoje vive seu filho. A marca da exclusão não foi alterada nas últimas gerações.

Portanto, atrás de crianças e adolescentes em abandono existem famílias abandonadas, esquecidas pelos programas das diferentes políticas sociais e negligenciadas até mesmo pela política de assistência social.

O Estatuto da Criança e do Adolescente reconhece o importante papel que a família desempenha no provimento das necessidades fundamentais de seus filhos, reservando um capítulo para a garantia do "Direito à Convivência Familiar e Comunitária”.

Quando trata da política de atendimento, o ECA recomenda como medida de proteção o retorno da criança ou do adolescente ao ambiente familiar (mediante termo de responsabilidade), a orientação, o apoio e a inclusão também da família em programas de auxílio, orientação ou tratamento.

Estes programas em geral inexistem ou se existem encontram-se de tal forma desar culados e tão pouco apoiados - técnica e financeiramente - que seus efeitos são pífios.
No contexto da cultura tutelar para com os empobreados dominante em nosso país, as atenções para com a família são conservadoras e inerciais e reafirmam o signo da subalternidade com ajudas em espec $\wedge$ le, eventuais e emergenciais, para mantê-las dependentes perpetuando o culto do "favor" e não a garantia do direito.

No entanto, é no espaço familiar que as necessidades fundamentais da criança e do adolescente tem sua primeira possibilidade de acolhida A faria é o lugar dos pertencimentos, dos abetos, dos conflitos e do suprimento dos bens materiais indispensáveis à manutenção da vida.

Muitas são as estratégias e os recursos utilizados pelo grupo familiar no sentido de garantir este viver cotidiano, continuamente ameaçado pelas contingências econômico-sociais da pobreza. Vive-se rotineiramente "sobre o fio da navalha” num cenário onde as carências materiais se misturam à violência e a discriminação.

Sem possibilidade de preparar com tranquilidade o futuro, as famílias pobres preocupamse com o presente e suas crianças são portadoras desses projetos de curto prazo, nos quais elas não são apenas receptoras mas também provedores.

Nas famílias em situação de pobreza, o modelo de família nuclear coexiste com novos arranjos familiares, cuja tônica é a família ampliada formada pelos parentes próximos ou conterraneos. Este núcleo constitui uma rede social primária de onde emergem ajudas fundamentais para a sobrevivência do grupo. Essa solidariedade conterrânea e parental ${ }^{3}$ garante os padrões mínimos de reprodução social, criando sistemas informais de trocas materiais além do apoio afetivo e das poucas oportunidades de lazer coletivo.

É nesse contexto que acontecem os acolhimentos informais de crianças pelos parentes ou amigos, quando as vicissitudes da miséria castram, temporária ou definitivamente, as possibilidades de permanência das crianças com seus pais biológicos. Nestas famílias, as crianças "circulam" e a responsabilidade direta por sua proteção é partilhada entre diferentes membros do grupo familiar amplo, especialmente pelas avós. ${ }^{4}$

Mesmo sendo um suporte fundamental de sobrevivência, esta solidariedade não pode ser supridora de todas as necessidades dos individuos no complexo mundo da modernidade atual. Reconhecer as necessidades do grupo familiar, significa contudo, sua aceitação como sujeitos e como agentes políticos e a inscrição de suas demandas no patamar dos direitos.

3 Cf. Pesquisa sobre Padroes de Reprodução Sodal na Sociedade Provid naa - Profa Aldaiza Sposati - PUC/SP 1990.

4 Sobrc a circulação de crianças veja-se: FONSECA, C. Criança, família e desigualdade social no Brasil. Ln RI ZZINI, 1 Criança no Brasil hoje: desatei o para o terceiro milênio. Rio de Janeiro, Ed. Un. Sta Urs a, 1993. 
Portando, para além dessa rede social básica, as famílias - evocando seus direitos - reivindicam sua inscrição nos programas oferecidos pelas redes institucionais públicas ${ }^{5}$ das diferentes políticas sociais. Nesta busca, defrontam-se quase sempre com a ausência destes serviços ou com uma oferta fragmentada, voltada muito mais para sujeitos individuais (a criança, a mulher, o idoso) do que para a fervia como sujeito coletivo.

A percepc,ão desses vazios de atendimento foi o motor de muitas ações coletivas com vistas à consolidação dos direitos sociais. Mas ai, também, a famosa foi subsumida pelos movimentos e organizações sociais ou sindicais, não se mostrando enquanto sujeito. Ao crescimento da ênfase no trabalho comunitário e na adesão aos movimentos sociais agregou-se o arrefecimento das experiências com famílias, embora as diferentes alternativas não tivessem que ser obviamente excludentes.

Por outro lado, se a ação pública secundarizou os programas de atendimento familiar, a rede de serviços sócio-comunitários de orientação religiosa voltou-se de forma mais ativa para este segmento. Esta solidariedade missionária representa não apenas um apoio espiritual mas também uma rede de apoio material e afetivo importante. Além disso foi ao abrigo dessas instituições que viscejaram alguns dos movimentos de luta por direitos, os quais viabilizaram várias conquistas em termos de serviços públicos.

Embora com uma atuação muitas vezes pontual e assistencial é pela via do apoio sócioreligioso que hoje se favorecem os canais de convivência e de solidariedade entre as famílias. Esta atuação das igrejas é bastante contraditório - por um lado abre espaço à participação e à organização popular na requisição de seus direitos, por outro, funciona como amortecedor das tensões sociais numa perspectiva acomodativa.

O ressurgimento da farn $\wedge$ l1ia hoje, enquanto unidade de atenção das políticas públicas, reflete uma retomada de consciência sobre a importância desta como provedora basica Indica também sua revitalizarão enquanto continente afetivo e espaço de reagregação de programas e investimentos dispersos e atomizados nas diversas redes institucioonais.

De todo modo é preciso considerar que a família tanto quanto a criança e o adolescente precisa de proteção social jurídica e económica.

Considerando-se que significativa parcela da população brasileira vive em situação de pobreza e outro tanto não desprezível vive de modo indigente, não há dúvida que qualquer proposta de política voltada para as fatias deve considerar as determinações estruturais dos proble mas que as envolvem. Nesta linha, a garantia de rendi mínima, a melhoria dos salários aliada à políticas dá geração massiva de empregos, assentamentos rurais e programas de segurança alimentar e de saúde, repre sentam um quadro básico para se começar o caminho dá alteração das desigualdades sociais.

Em termos estratégicos é preciso ainda que se garantam patamares de melhor qualidade em programas dá saúde, educação e habitação, por exemplo.

Entretanto, este esforço global deve ser conjugada a programas de atenção direta de Assistência Social à famílias mais vulnerabilizadas ampliand se, tambén para elas, a proteção reivindicada para crianças e adoles centos dos grupos de risco.

Tais programas podem ser caracterizados por níveis de atenção e complexidade compreendendo a orientação os apodos ou auxílios, os programas promocionais e os terapêuticas.

No nível da orientação, encontram-se programa (sistemáticos ou assistemáticos) dirigidos a uma famíli; ou a grupos de famílias, numa linha mais preventiva e educativa São exemplos: os grupos de gestantes, de pia nejamento familiar e algumas atividades do plantão socia enquanto recebimento de demandas e oferta de informa ção básica.

Num segundo nível é preciso que se organizem o programas de apoio ou auxílio. Esse apoio tem se carac terizado mais pela ajuda material em situação dá emergência do tipo “cesta-básica”, enxoval para o beba etc. Um auxílio financeiro direto como já vem sendo feita pelo IAFAM (Instituto de Assuntos da Família - SP) é indispensável para que a família se reorganize de moda emancipado e responsável. É necessário pensar tambén neste apoio financeiro para fiam filas de acolhimento como “bolsa-desenvolvimento” para crianças sem condições de estar com sua própria família.

No entanto, a sustentação financeira não é o única apoio de que a família necessita. Ela precisa tambén de apoio psico-social para o enfrentamento das situações mais difíceis, dos conflitos familiares, da ausência prolongada de renda, etc., incluindo-se aí o apoio jurídico.

Muitas vezes as famílias mais pobres carecem Iam bem de apoio informativo no senado de localizá-los em relação aos recursos e serviços existentes os quais na são procurados por desconhecimento.

Um outro nível de atendimento às famílias caracteriza-se pelos programas de desenvolvimento

5 A análise faz parte das reflexões contadas no Relatório Preliminar de Pesquisa sobre as Redes de Atençao à Criança e ao Adolescente - EE^/PUC CBIA-1 994. 
que visam fortalecer os ganchos de poder. São desse tipo as ações voltadas à preparaçao profissional; o encanunhamento a emprego e projetos de geração de renda. Também são promocionais os programas voltados à socialização, ao lazer e à cultura que buscam elevar o padrão de cidadania do grupo familiar.

Por fim, quando o grupo familiar está mergulhado em patologias ou diificuldades emocionais mais complexas, sua demanda precisa ser atendida de modo direto e sistemático por serviços de saúde mental. Os programas terapêuticos são indicados quando uma açao mais indiretaou grupal mostra-se incapaz de reverter os problemas ou quando estes são mais profundos e já comprometeram a dinâmica do convivio.

Evvidentmente, uma família poderá se socorrer concomitantemente dos vários tipos de programas protetivos ou apenas de um ou outro, dependendo do caso.
De todo modo, é importante que todos esses serviços sejam organizados numa "rede de proteção à família" que intercambie informações e serviços e promova atendimento e encaminhamento de forma integrada e eficaz.

Esta rede de atenção à família precisa focar a faília não apenas pelo seu núcleo central os pais - em muitos casos reduzido apenas à figura materna. O grupo familiar pode ser considerado pela e tensão de sua rede básica primária onde, figuras parentais agregadas conpõem usualmente elos de apoio, autoridade ou afetividade fundamentais para o desenvolvimento da criança e do adolescente.

Para dispor-se a estender a proteção à família é preciso também re-significá-la a partir de uma nova atitude para com ela. Neste mister, é preciso superar condutas pautadas na visão da família como incapaz, incompetente desestruturada ou culpada.

recebido em: 07/06/94

aprovado em: 26/08/94 